\title{
Wear Study On Al-B4C Composite Material
}

\author{
N. Pavan ${ }^{1 *}$, Jaysaheel I. Harti ${ }^{2}$, K. S. Harishanand ${ }^{3}$ \\ ${ }^{I}$ M.Tech. Student, Department of Mechanical Engineering, East Point College of Engineering and Technology, \\ Bengaluru, India \\ ${ }^{2}$ Assistant Professor, Department of Mechanical Engineering, East Point College of Engineering and \\ Technology, Bengaluru, India \\ ${ }^{3}$ Professor \& HoD, Department of Mechanical Engineering, East Point College of Engineering and Technology, \\ Bengaluru, India \\ *Corresponding author: pavan.veer0709@gmail.com
}

\begin{abstract}
There are various types of engineering materials used in both commercial as well as non-commercial applications, it becomes important to think about the life of the material, to prove about the economical aspect of the material.

In order to increase the life, the conventional engineering materials fails in one or the other aspects. So the arrival of composite materials is important, which shows better mechanical properties than the regular engineering materials with lower weights.

A study on the wear behaviour of a composite material (Al$\mathrm{B} 4 \mathrm{C}$ ), under varying concentration of the reinforcement is made to understand the material usability under the cyclic operating conditions.
\end{abstract}

Keywords: Al-B4C, Composite, Material, Wear.

\section{Introduction}

\section{A. Need of composite material}

As, the industrial requirement for low weight and durable materials are increasing, it becomes mandatory for the engineers to come out with wide range of materials with better mechanical properties along with the condition of lower weight ratios.

The demand for the optimal material for a definite application in day today life in industry as well as in noncommercial aspects is continuously increasing.

It is noticed through the various research aspects that, the demand for the never ending industrial requirement can be fulfilled only through the composite materials.

\section{Synthesis of Composite Material}

Stir-casting method is employed for the synthesis of the composite materials. In this technique, the base material ( $\mathrm{Al}$ 1100 ) is brought to the liquid state and the reinforcement is dispersed in the molten liquid, the mixture is continuously stirred to get a homogeneous mixture.

The homogeneous mixture so obtained is poured in a mould box, whose dimensions are as follows $24 \mathrm{~mm}$ diameter and length $190 \mathrm{~mm}$ and second type of mould with four cavities of $20 \mathrm{~mm}$ diameter and length $200 \mathrm{~mm}$ and allowed for sonification.

The process is repeated to obtain the composite material for various composition of reinforcement.

6 different composition of composite material is casted by varying the composition by $1 \%$ by mass starting from $1 \%$ is casted for conducting the test to know the material behaviour.

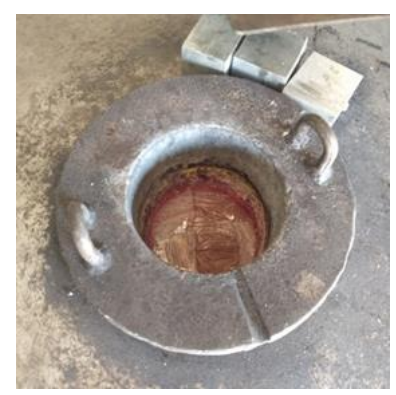

(a) Clay graphite crucible

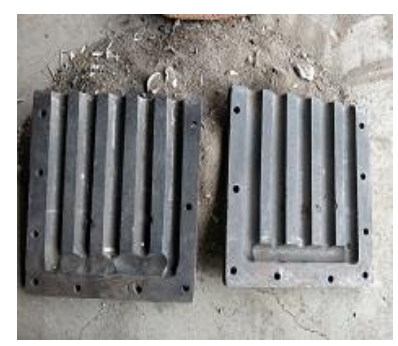

(b) Mould box

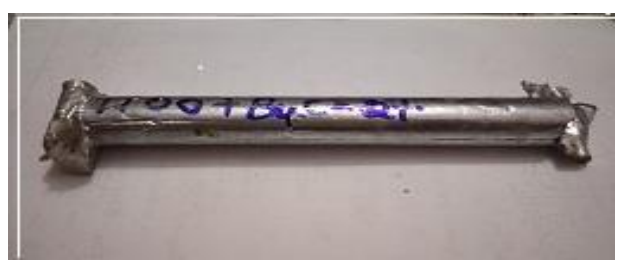

(c) Casted product

Fig. 1.

\section{Methodology}

The test was carried out on various specimens for sliding velocity of $2.09 \mathrm{~m} / \mathrm{s}$ and sliding distance of $1900 \mathrm{~m}$ at $1000 \mathrm{rpm}$, 
Volume-3, Issue-10, October-2020

\section{IJRESM journals.resaim.com/ijresm | ISSN (Online): 2581-5792 | RESAIM Publishing}

$4.18 \mathrm{~m} / \mathrm{s}$ and $3800 \mathrm{~m}$ at $2000 \mathrm{rpm}$. With the increase in the percentage of reinforcement particle, it was found experimentally that there is a gradual reduction the wearing behaviour of the material. The figure belowgives the details about variation of wear with concentration of reinforcement particle. The decrease in wear is due to decrease in amount of plastic deformation at contact region due enhancement in hardness of the composite with inclusion of reinforcement.

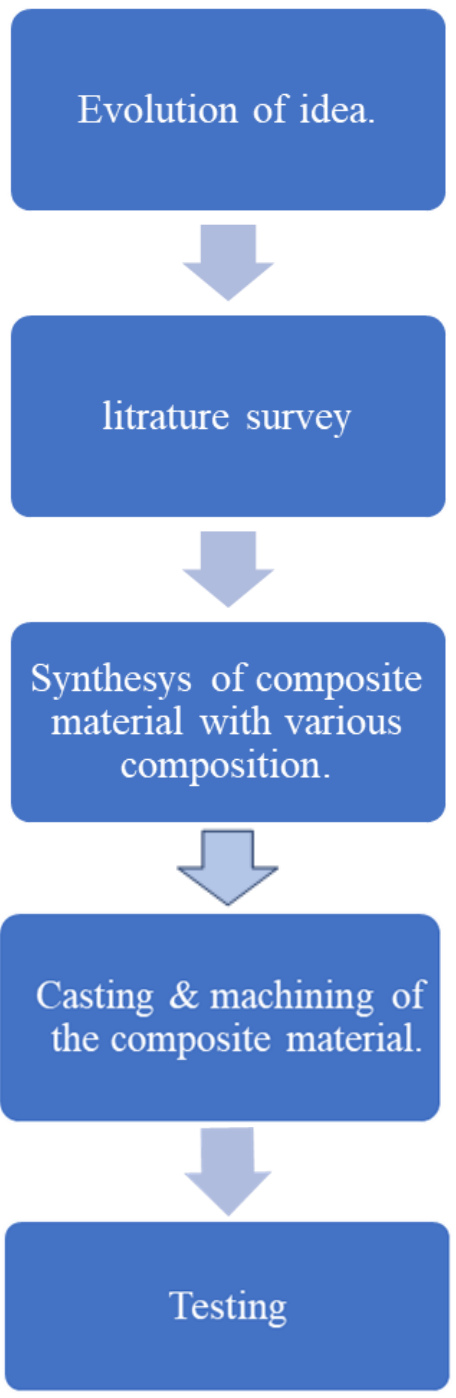

Fig. 2. Flowchart

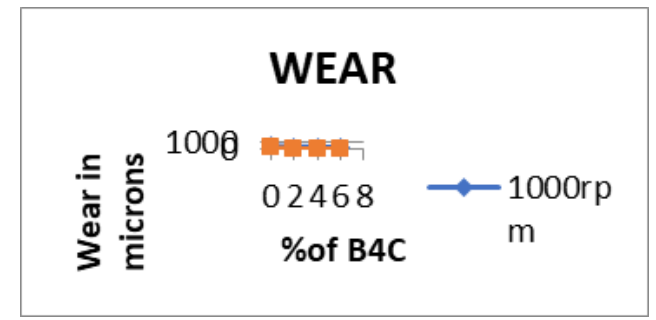

Fig. 3. Variation of wear rate with \% of B4C reinforcement

The variation of coefficient of friction is shown in figure below It can be observed that the coefficient of friction is lower for composite with higher percentage of reinforcement which is attribute to abrasive nature of wear caused due to increased hardness.

\section{Coefficient of friction}

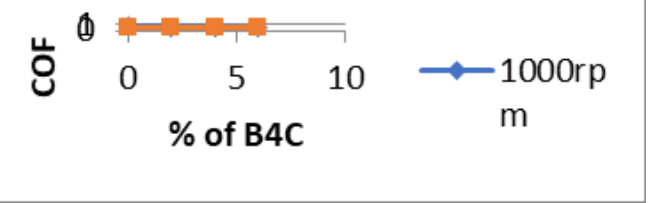

Fig. 4. Coefficient of friction

Figure shows the experimental graphs of wear, frictional force and coefficient of friction for $0 \%$ (purple), $1 \%$ (red), $3 \%$ (blue), 5\%(green) B4C reinforcement for $1000 \mathrm{rpm}$ and 2000rpm obtained from the pin on disc wear test machine.

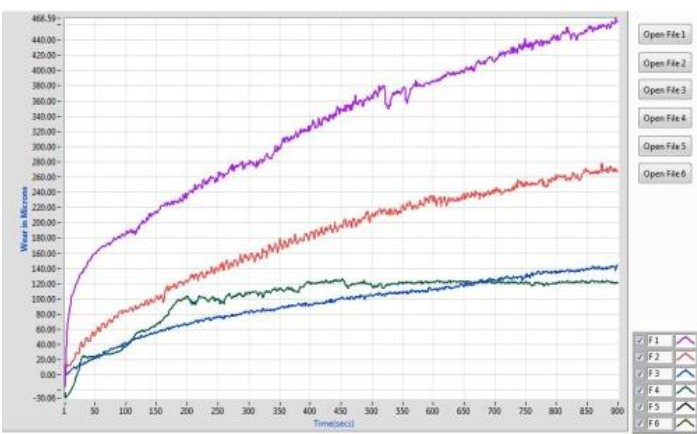

Fig. 5. Wear at 1000rpm

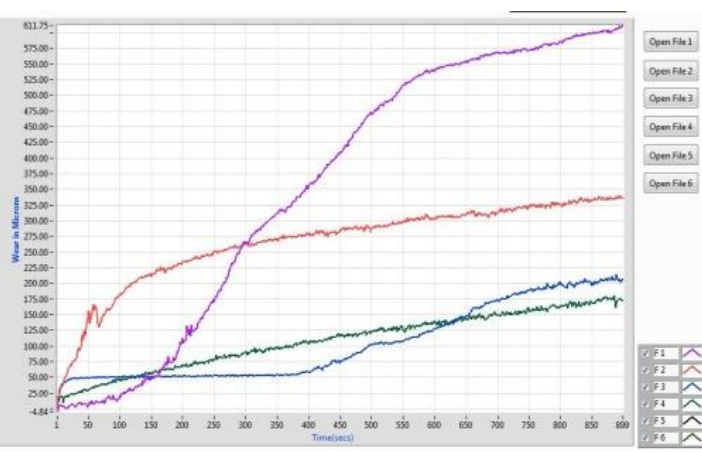

Fig. 6. Wear at 2000rpm

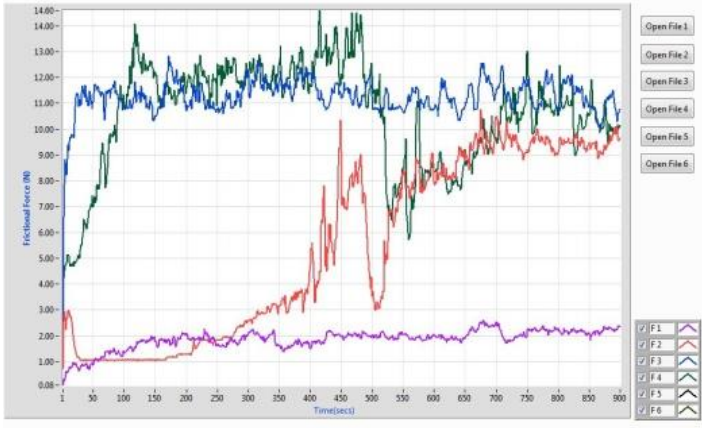

Fig. 7. Frictional force at 1000rpm 


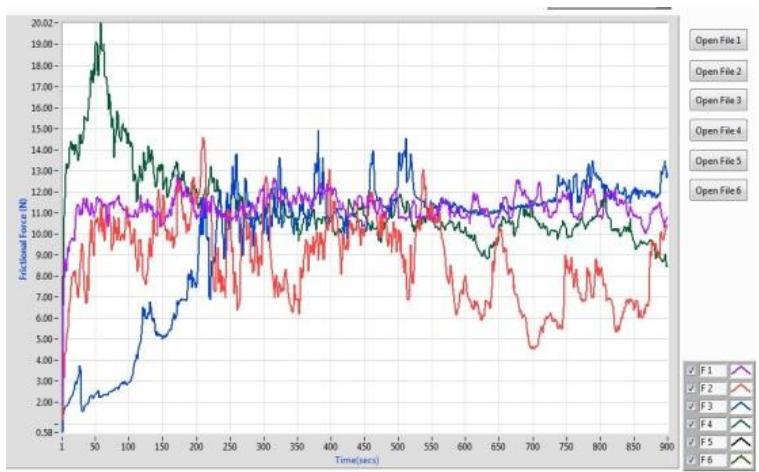

Fig. 8. Frictional force at $2000 \mathrm{rpm}$

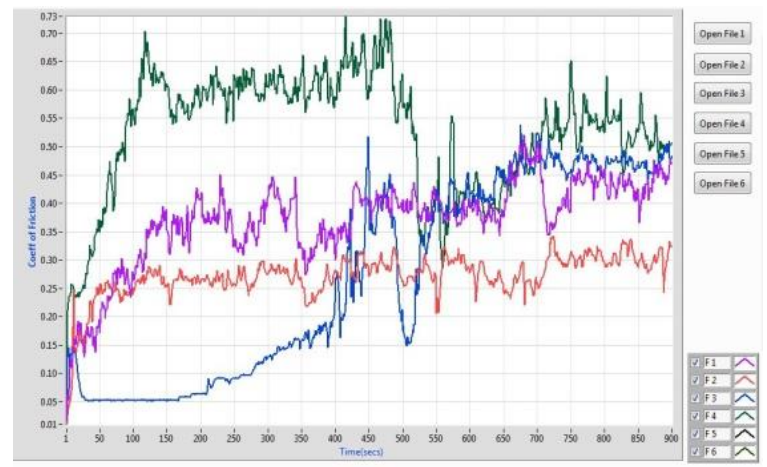

Fig. 9. Coefficient of friction at 1000rpm

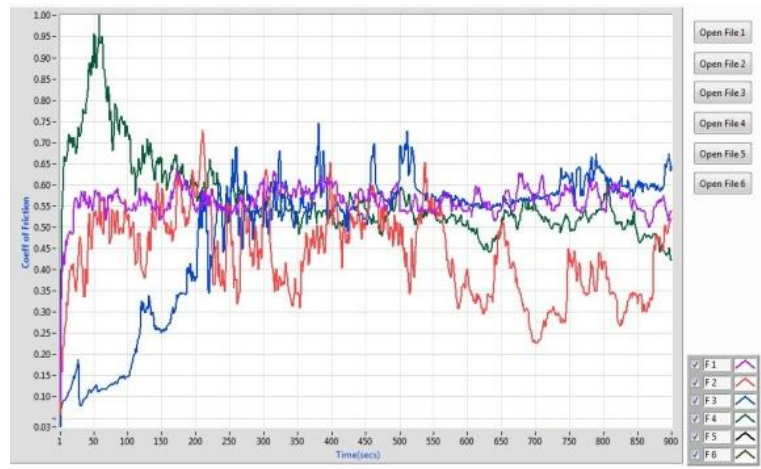

Fig. 10. Coefficient of friction at 2000rpm

\section{Conclusion}

The study clearly indicates the decrease in the wear rate, i.e. the wear behaviour is been improved considerably which suits the expected requirement. Depending on the requirement and operating condition, one has the freedom to select the suitable concentration of reinforcement in the composite material for the application.

\section{References}

[1] R. C. Adams, et.al, "ASM Metals handbook", vol. 21, 2001.

[2] Autar K. Kaw, "Mechanics of Composite materials", 2nd edition, 2006.

[3] S.V. Prasad and R. Asthana, "Aluminum metal-matrix composites for automotive applications: tribological considerations", Tribology Letters, Vol. 17, No. 3, October 2004.

[4] B. Prabhu, C. Suryanarayana, L. An, R. Vaidyanathan, "Synthesis and characterization of high volume fraction $\mathrm{Al}-\mathrm{Al}_{2} \mathrm{O}_{3}$ Nano composite powders by high-energy milling", Mater. Sci.Eng. A 425 (2006) 192-200.

[5] P. Ashwatha, M. Anthony Xavier, "The Effect of Ball Milling \& Reinforcement Percentage on Sintered Samples of Aluminum Alloy Metal Matrix Composites", Journal on 12th Global Congress on manufacturing and management, Vol. 97, 2014, pp. 1027-1032.

[6] Chuandong Wu, Pan Fang, Guoqiang Luo, Fei Chen, Qiang Shen, Lianmeng Zhang, Enrique J. Lavernia, "Effect of plasma activated sintering parameters on microstructure and mechanical properties of A17075 and B4C composites", Journal of Alloys and Compounds, Vol. 615, (2014), pp. 276-282.

[7] Auradi, Rajesh and S. A. Kori, "Processing of B4C Particulate Reinforced 6061 Aluminum Matrix Composites by melt stirring involving two step addition”, Procedia Material Science, Vol. 6, (2014), pp. 1068-1076.

[8] Pradeep V. Badiger, Virupakshi Auradi, Rajesh G. L, Vijay Kumar Hiremath, "Investigation on Mechanical Properties of B4C Particulate Reinforced Al6061 Metal Matrix Composites", International Journal of Applied Engineering Research, Vol. 10, No.71 (2015).

[9] Vettivel, A. Baradeswaran, A. Elaya Perumal, N. Selvakumar, R. Franklin Issac, "Experimental investigation on mechanical behavior, modelling and optimization of wear parameters of B4C and graphite reinforced aluminum hybrid composites", Materials and Design, Vol. 63, (2014), pp. 620-632.

[10] Canakci and F. Arslan "Abrasive wear behavior of B4C particle reinforced Al2024 MMCs”, Int J. Adv. Manuf. Technol., Vol. 63, (2012), pp. 785-795.

[11] Baradeswaran, A. Elaya Perumal, "Influence of B4C on the tribological and mechanical properties of $\mathrm{Al} 7075$ and B4C composites", Composites: Part B, Vol. 54, (2013), pp.146-152.

[12] Gopal Krishna U. B, Sreenivas Rao K. V, Vasudeva B, "Effect of boron carbide reinforcement on Aluminum matrix composites", IJMMSE, Vol. 3, Issue 1, Mar 2013, pp. 41-48.

[13] Ibrahim, H. R. Ammar, A. M. Samuel, M. S. Soliman, A. Almajid and F. H. Samuel, "Mechanical properties and fracture of Al 15 vol\% B4C based metal matrix composites", International Journal of Cast Metal Research, vol. 27, no 1, 2014.

[14] Kalaiselvan, N. Murugan, Siva Parameswaran V, "Production and characterization of Al 6061 and B4C stir cast composite", Materials and Design, Vol. 32, pp. 4004-4009, 2011.

[15] Muthazhagan, A. Gnanavel Babu, G. B. Bhaskar and K. Rajkumar, "Influence of Graphite Reinforcement on Mechanical Properties of Aluminum and Boron Carbide Composites", Advanced Materials Research, vol. 845, pp. 398-402, 2014. 